\title{
Simulation Modeling in Prior-Posterior Decision Theory- A Case Study of Farmers' Decision Problem
}

\author{
Dr. Eme Luke Chika, (B.Sc, PGD, PGDE, M.Eng, Ph.D), \\ Civil Engineering Department, Chukwuemeka Odumegwu Ojukwu University \\ (formerly Anambra State University), Uli - Nigeria \\ Ohaji Evans, (B.Eng, M.Eng) \\ Rural Infrastructural Engineer, Implementation Field Office, \\ Niger Delta Support Programme Component, Imo State, Nigeria
}

\begin{abstract}
This study aims at applying Prior-Posterior decision theory based models to analyze and solve the farmers' decision problem who are faced with decision of determining among alternatives crops [Sorghum, Rice, Wheat \& Corn] the best crop to invest on, that will give a highest yield and profit under the prevailing state of nature on each of a 100 acres land located in Obudu LGA in Cross River State for each of the Farm Settler. However, the study has the following objectives (i) laying bare the usefulness of the theory, (ii) measuring the magnitude of the difference between alternative actions (iii) presenting experimental results for considering decision making under uncertainties, and (iv) evaluating the optimal policy or strategy or action that maximizes the expected yield of cereal crop within the study area. The methodology involves experiments and data were compared to United State Department of Agriculture (USDA). The analysis and presentation of results were based on Simulation of Prior-Posterior decision models, Policy iterations, and Pearson Product Moment Correlation as interaction, validity, reliability tests respectively. Consequently, from the results of prior probabilities of the state of nature and the likelihood of the alternatives courses of action, and applying Prior-Posterior Decision Models to the uncertain system, the following decision were generated: (a)Posterior Probabilities of the States of Nature (b) Marginal Probability of the Course of Action, (c) Maximum Expected Monetary Value[EMV*] (d) Expected Profit in a Perfect Information[EPPI], (e) Expected Value of Perfect Information[EVPI], and (f) Expected Value of System Information[ EVSI]. The results gave a clear indication that Rice has the [EMV*] value of $\$ 17,178.21$ at $40^{\text {th }}$ model iteration, making it the most suitable crop for each of the Farmer Settlers to invest on, for maximum yield. EMV* of rice was also observed to be optimized from the $1^{\text {st }}$ and $40^{\text {th }}$ model iteration at the value of $\$ 14,175.66$ and $\$ 17,178.21$ respectively. The results of the analyses attest to the fact that rice production in Obudu study area is currently the most yielding crop. The performance of Prior-Posterior decision models on the farmers' decision was evaluated which gave Pearson Product Moment Coefficient(r) of $=1.0$. This shows applicability of Prior-Posterior Decision Model Excel Algorithms in River Basin Multi-projects/objectives Planning and Management.
\end{abstract}

Keywords: Prior-Posterior, Modeling, Farm- Settlers -Decision, investment, Optimization.

DOI: $10.7176 / \mathrm{CER} / 11-2-07$

Publication date:March $31^{\text {st }} 2019$

\subsection{Introduction}

Farmers in Obudu LGA in Cross River State was confronted with an economic decision of selecting the best cereal crop to invest on, in the area. An investment that will actually bring in the dividend of agriculture as the federal government is clamoring for all to go into agriculture to save Nigerian from food scarcity and as well as gains from foreign exchange earnings through cereal crops exports. Against the foregoing, the farmers needed a consultant who can handle the said problem that is shrouded on uncertainties. However, details of the solution to the problem is handled step-wisely as you proceed in this paper.In Prior-Posterior decision model, it is difficult to consider decision problems in which the decision maker has no information, either objective or subjective, regarding the probabilities of the states of nature.

Agricultural production in developing cities like Obudu, Cross River State, Nigeria is subject to a number of risks including flood that can lead to large fluctuations in output and prices of agricultural commodities. These fluctuations result in uncertain incomes for producers, and unstable availability of work for agricultural laborers.

\subsection{Area of Study}

Obudu Dam is in Obudu Local Government Area of Cross River State in the South East of Nigeria. It is an earthfill structure with a height of $15 \mathrm{~m}$ and a total crest length of $425 \mathrm{~m}$, and has a capacity of 4.2 million $\mathrm{m}^{3}$.The dam is located within the Obudu crystalline basement plateau, a low-lying undulating region of low seismic activity. The dam was commissioned in 1999 for use in farm irrigation, fishing, and also for recreational and tourism purposes.(www.wikipedia.org). However, the adjoining Piece of Land selected for the research work is 
about 100meters from the Dam for irrigation purposes.

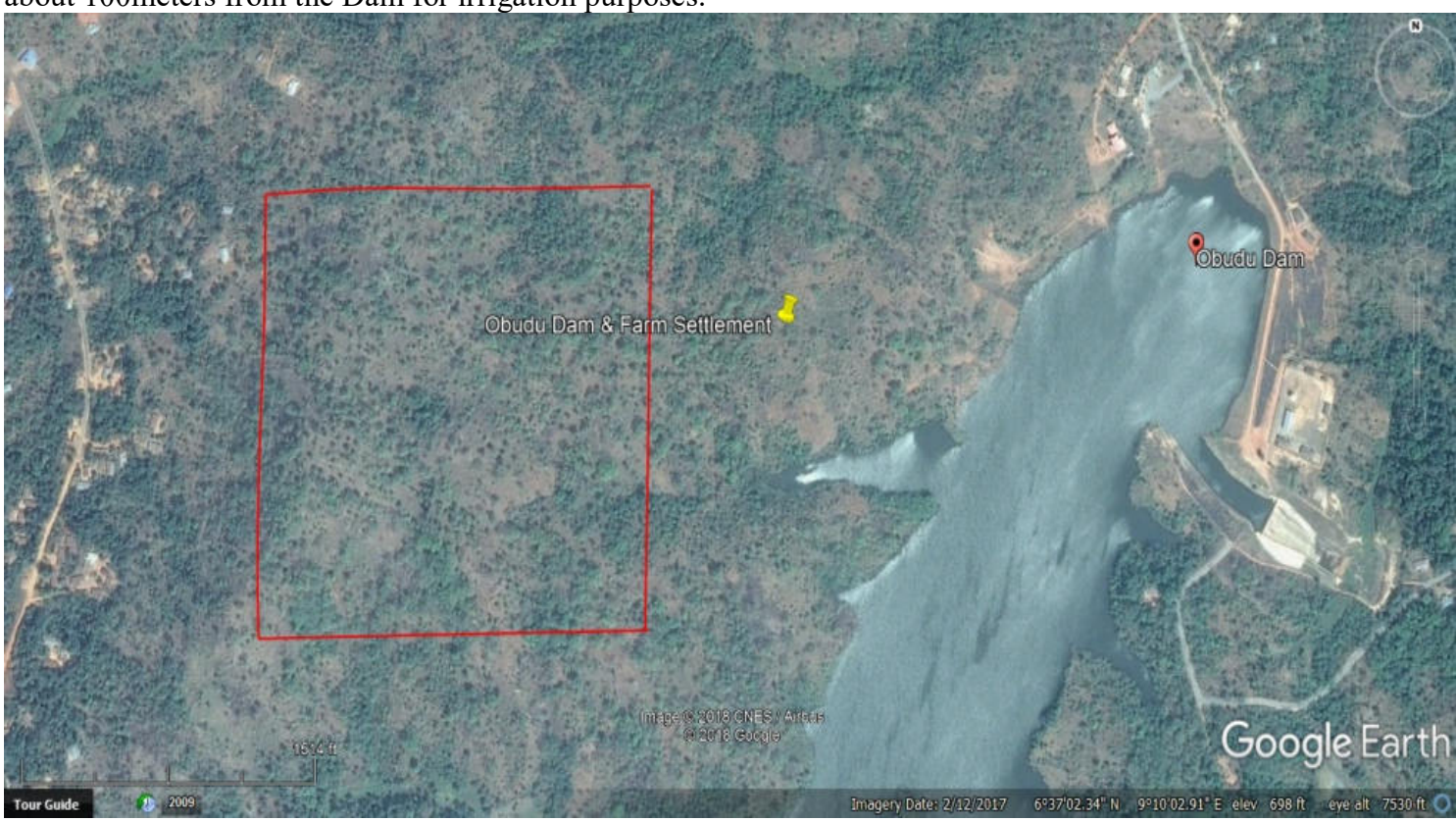

Figure 1: Aerial View: Obudu Dam \& Farm Settlement Land

The area of study is Obudu Dam and an adjoining Farm Settlement Land measuring 100 acres located in Obudu LGA, Cross River State, Nigeria, with a GPS of 6³5'51.81" N 9 $9^{\circ} 11^{\prime} 07.54 "$ E, in the south-south part of the country, near the border with Cameroon.

\subsection{Methodology}

The methodology applied is as explained in the empirical framework in section 2.5. However, to estimate the crop that will produce the utmost yield among various alternatives on the account that the production/yield of the four cereal alternatives is influence by climate water per year, the horizon for the observation is from 2014 to 2017. A Bayesian Decision Theory Model will be used to simulate the system for an optimum result. The mathematical model is of the form:

\section{P (A/DATA $)=[$ P (DATA/A) X P (A) $] /$ P (DATA) \\ Equation 1}

Where:

A -the Climate per years of cereal productions [2014, 2015, 2016 and2017].

DATA- Cereal crops yield per year.

P (A/DATA)-Probability of A occurring given the DATA [Posterior Probability].

P (DATA/A)-Probability of the Data occurring given the Year.[Likelihood Forecast].

P (A)- Prior Probability of A[Prior Probability of A].

P (DATA)- Probability of DATA occurring[ Marginal Probability or Evidence].

The Bayesian formula as stated above is used in the development the following spread sheets:

All the excel spread sheets are connected together and run as a model by inputting initial objective/subjective state of Nature Prior, in this case we had an objective prior [ see table 1]. Which when inputted automatically generates the outputs. However, the posterior probability generated is in turn inputted as a new prior in the next simulation process; these processes continue until a near optimum solution is reached. The number of iteration ranges from 1,2,3,4 to $\mathrm{N}$ [N means optimum point]. Running the Model up to the point of optimum is necessary because it gives the researcher/expert the following edge:

(i) Gives idea of the money to be paid to the experts for providing useful information for the model development in form of EVPI and EVSI. (ii) Gives idea to the researcher on, least cost to be incurred on the selected crop that has the maximum EMV. (iii) Gives idea to the researcher on the ultimate prior probability that will give each of the Farm Settler the absolute decision i.e. the priority that produces the optimum solution, gives the actual indication of the state of nature. 


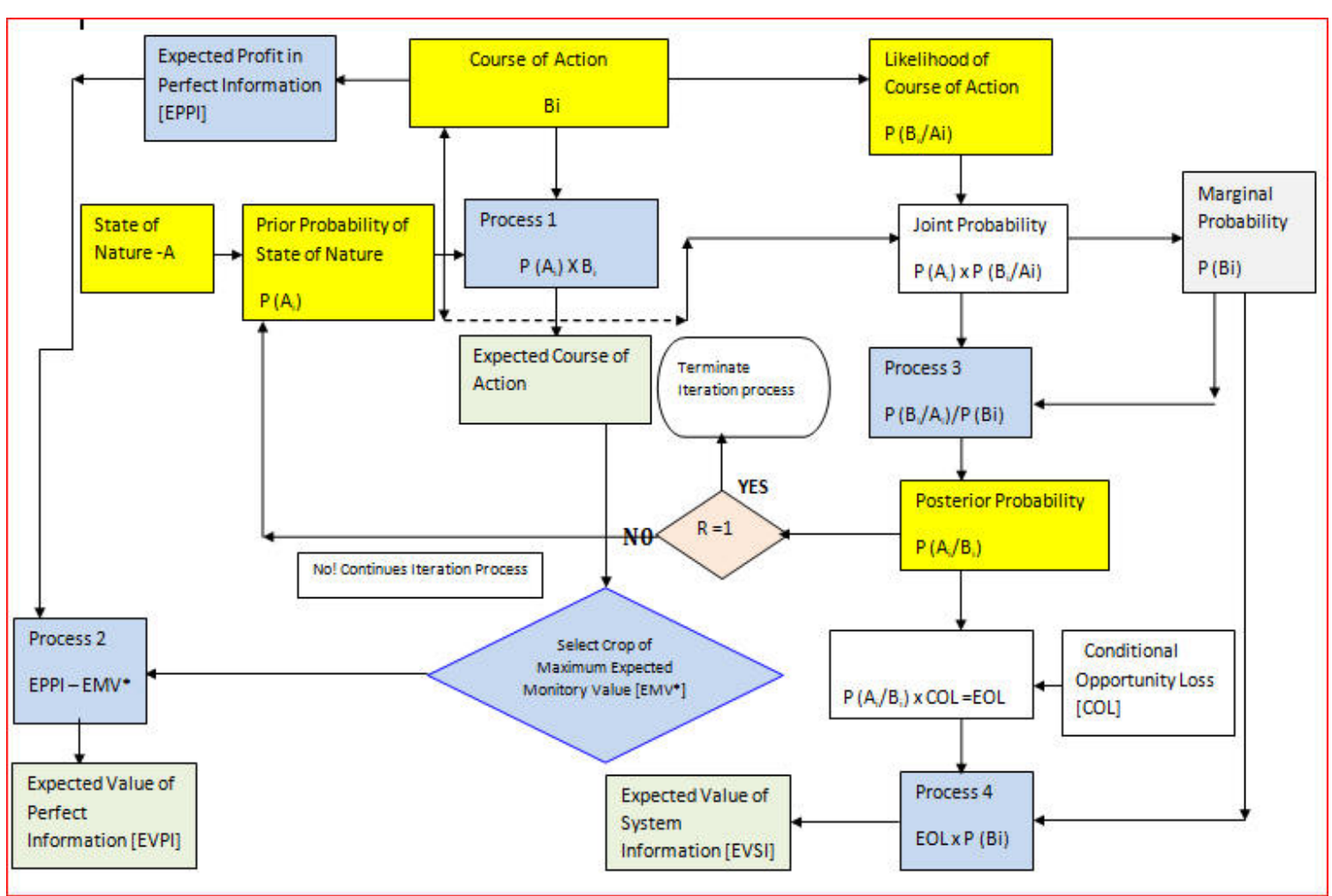

Figure 2: Prior-Posterior Decision Theory Flow Chart

\subsection{Data Gathering, Analysis and Application of Bayesian Decision Model to Farmer's Problem}

The study was designed to cover a period of 4 years $(2014-2017)$. Series data in respect of annual yields ( $t$ ha1) of Maize, Rice, Sorghum and Wheat was obtained from the United State Department of Agricultural (USDA); the data on climateis not known[State of Nature], however, the Prior probability of the climate was estimated based on the crops growth rate. The Prior will be correlated with posterior probability by using Pearson Product Moment Correlation Coefficient[Pearson r] after posterior probability is generated by Bayesian decision model.

Suppose a farmer is attempting to decide which of the four crops he should plant on his 100 acre farm come next year 2019. The profit from each crop is strongly dependent on the climate during the growing season per year. He has selected four years horizon form 2014-2017 to enable him make optimum decision for higher yield and profit. Based on the production growth rate from 2014 to 2017 as shown in Table1.

\subsubsection{State of Nature}

According to Bullock et al (1969); the state of nature can also be defined as the value of one or more exogenous factors that directly affects the outcome of a particular action that cannot be controlled with certainties by the decision maker.

This is known as random variable. For this study and owning to the varying weather condition and scares availability of water which reflected on the crops as "crop growth rate" however the crop growth rate will be used to calculate the prior probability $\mathrm{A}_{\mathrm{j}}$ of the state of nature. The crop growth rate which gives indication of state of nature is a random variable. Tablel shows the 4-years(2014 to 2017) crop growth rate as well as four state of nature and are considered based on the deductions made as follows: Substantial, Moderate, Fair and Slightly fair.

Conditional Probability: Since $A_{j}$ is a random variable which the farmer needs to know more about to make correct decision

Calculation of Prior Probability: From the prior experience, the conditional probability distribution of such observation can be computed.

Posterior Probability: Here conditional probability is applied; where the Prior probability of the state of nature is multiplied by the likelihood probability, whose sum also results to marginal probability. However, the conditional probability when divided by the marginal probability result to Posterior Probability. 
Table 1: Estimation of Prior using production growth rate

\begin{tabular}{|l|l|l|l|l|l|l|}
\hline State of Nature & \multicolumn{4}{|l|}{ Crops Production growth rate } & Estimated Prior \\
\hline Climate (A) & sorghum & Millet & Wheat & Corn & Sum & \\
\hline Substantial & 27.19 & 52.2 & 0 & 28.11 & 107.5 & 0.686155614 \\
\hline Slightly Fair & 0 & 6.64 & 0 & 0 & 6.64 & 0.042382077 \\
\hline Moderate & 21.59 & 14.62 & 0 & 0 & 36.21 & 0.231122742 \\
\hline Fair & 0 & 6.32 & 0 & 0 & 6.32 & 0.040339567 \\
\hline & & & & & 156.67 & 1.000000000 \\
\hline
\end{tabular}

Table 2: Prior Probability \& Course of Action at the $1^{\text {st }}$ Iteration

\begin{tabular}{|r|ll|l|l|r|r|}
\hline State of Nature & $\begin{array}{l}\text { Prior Probability of State of } \\
\text { Nature }\end{array}$ & \multicolumn{5}{|c|}{ Course of Action $\{$ B) [\$] } \\
\hline Environmental Factor[A] & $\mathrm{P}(\mathrm{A})$ & Sorghum & Rice & Wheat & Corn \\
\hline Substantial & & 0.686155614 & $9,058.99$ & $14,117.29$ & $10,376.91$ & $11,946.10$ \\
\hline Slightly Fair & 0.042382077 & $7,050.76$ & $13,044.87$ & $7,448.50$ & $8,713.80$ \\
\hline Moderate & 0.231122742 & $6,710.72$ & $14,074.21$ & $6,068.07$ & $9,594.03$ \\
\hline Fair & 0.040339567 & $6,704.19$ & $\mathbf{1 7 , 4 3 3 . 5 2}$ & $6,344.88$ & $9,089.70$ \\
\hline
\end{tabular}

The outcome of Table 1 is enlisted in column 2 of table 2 which serves as the prior probability of the state of nature. Hence table 2 can be called Pay Matrix. The likelihood of the observed data is calculated as shown in table 3.

Table 3: Likelihood Forecast

\begin{tabular}{|r|r|r|r|r|}
\hline State of Nature & P(B1/A1) & P(B1/A1) & P(B1/A1) & P(B1/A1) \\
\hline Substantial & 0.199101788 & 0.310275 & 0.228068 & 0.262556 \\
\hline Slightly Fair & 0.194461184 & 0.35978 & 0.205431 & 0.240328 \\
\hline Moderate & 0.184122547 & 0.386155 & 0.16649 & 0.263232 \\
\hline Fair & 0.169416276 & 0.440549 & 0.160336 & 0.229699 \\
\hline
\end{tabular}

\section{Bayesian Decision Modeling and Simulation processes}

$1^{\text {st }}$ Iteration Process

In line with the Bayesian Decision Flow Chart (Fig.2), the Products of Prior Probability generated from table 1 $\&$ Course of Action of table 2 and then Table 3 [ $1^{\text {st } I t e r a t i o n] ~ r e s u l t e d ~ t o ~ t h e ~ f o l l o w i n g ~ o u t p u t: ~ T a b l e ~ 4, ~ T a b l e ~ 5, ~}$ Table 6, Table 7 and, Table 8

Table 4: Expected Monetary Value at the $1^{\text {th }}$ Iteration

\begin{tabular}{|c|c|c|c|c|}
\hline State of Nature & Expected & e of Action & & \\
\hline Environmental Factor[A] & Sorghum & Rice & Wheat & Corn \\
\hline Substantial & 6215.88 & 9686.66 & 7120.18 & 8196.88 \\
\hline Fair & 298.83 & 552.87 & 315.68 & 369.31 \\
\hline Moderate & 1551.00 & 3252.87 & 1402.47 & 2217.40 \\
\hline Slightly Fair & 1551.00 & 703.26 & 0.00 & 366.67 \\
\hline EMV & $9,616.70$ & $14,195.66$ & $8,838.33$ & $11,150.27$ \\
\hline
\end{tabular}

EMV (Course of action, $\mathrm{S}_{\mathrm{J}}=\sum_{l=1}^{\mathrm{m}} \mathrm{Pij} \mathrm{Pj}$

Equation 2

$\mathrm{EMV}^{*}=\sum_{j=1}^{m} \mathrm{Pij} \mathbf{P} \mathbf{j}=\mathbf{1 4 , 1 9 5 . 6 6}$

The Maximum Expected Monetary Value from Table $4=\mathbf{1 4 , 1 9 5 . 6 6}$

Table 5: EVSI

\begin{tabular}{|l|r|r|r|}
\hline Outcome & Marginal Probability & EOL & EVSI \\
\hline C1 & 0.19 & 4453.375894 & 865.0485201 \\
\hline C2 & 0.34 & 5527.319512 & 1852.569045 \\
\hline C3 & 0.21 & 7087.341658 & 1489.361956 \\
\hline C4 & 0.26 & 10308.78497 & 2684.867189 \\
\hline & & & $\$ 6,891.85$ \\
\hline
\end{tabular}

$\mathbf{\$ 6 , 8 9 1 . 8 5}$ is the EVSI the Farmer has to pay for hiring the services of the forecaster at the $1^{\text {st }}$ Iteration. $2^{\text {nd }}$ Iteration Process

Similarly, in line with the Bayesian Decision Flow Chart (Fig.2), the Products of Posterior Probability( $2^{\text {nd }}$ Iteration Prior) generated in table $6 \&$ Course of Action of table 2 and Table 3 resulted to the following outputs: Table 7 and, table 8 (a), (b), and (c). 
Table 6: Prior Probability \& Course of Action at the $\mathbf{4 0}^{\text {th }}$ Iteration

\begin{tabular}{|r|lr|r|l|r|r|}
\hline State of Nature & $\begin{array}{l}\text { Prior Probability of State of } \\
\text { Nature }\end{array}$ & \multicolumn{5}{|c|}{ Course of Action\{B)[\$] } \\
\hline Environmental Factor[A] & $\mathbf{P}(\mathbf{A})$ & & Sorghum & \multicolumn{1}{l|}{ Rice } & Wheat & Corn \\
\hline Substantial & 0.01 & $9,058.99$ & $14,117.29$ & $10,376.91$ & $11,946.10$ \\
\hline Fair & 0.02 & $7,050.76$ & $13,044.87$ & $7,448.50$ & $8,713.80$ \\
\hline Moderate & 0.04 & $6,710.72$ & $14,074.21$ & $6,068.07$ & $9,594.03$ \\
\hline Slightly Fair & 0.93 & $6,704.19$ & $17,433.52$ & $6,344.88$ & $9,089.70$ \\
\hline
\end{tabular}

Table 7: Expected Monetary Value at the $40^{\text {th }}$ Iteration

\begin{tabular}{|r|r|r|r|r|}
\hline \multicolumn{1}{|c|}{ Expected Course of Action } \\
\hline \multicolumn{1}{|c|}{ Environmental Factor[A] } & \multicolumn{1}{|c|}{ Sorghum } & \multicolumn{1}{l|}{ Rice } & \multicolumn{1}{l|}{ Wheat } & \multicolumn{1}{c|}{ Corn } \\
\hline Substantial & 90.59 & 141.17 & 103.77 & 119.46 \\
\hline Fair & 141.02 & 260.9 & 148.97 & 174.28 \\
\hline Moderate & 268.43 & 562.97 & 242.72 & 383.76 \\
\hline Slightly Fair & 268.43 & 16213.17 & 0 & 8453.42 \\
\hline & 768.46 & $\mathbf{1 7 , 1 7 8 . 2 1}$ & 495.46 & $9,130.92$ \\
\hline
\end{tabular}

EMV (Course of action, $\mathrm{S}_{\mathrm{J}}=\sum_{7-1}^{m}$ Pij $\mathbf{P j}$

$\mathrm{EMV}^{*}=\sum_{j=1}^{\mathrm{m}} \mathrm{Pij} \mathrm{P}$ =17,178.2

Equation 3

Table 8 (a): Expected Value of System Information[EVSI]

\begin{tabular}{|c|c|c|c|}
\hline Outcome & Marginal Probability & EOL & EVSI \\
\hline $\mathrm{C} 1$ & 0.17 & 2223.069 & 379.705177 \\
\hline $\mathrm{C} 2$ & 0.44 & 4316.234 & 1879.52477 \\
\hline $\mathrm{C} 3$ & 0.16 & 4552.022 & 738.164027 \\
\hline $\mathrm{C} 4$ & 0.23 & 8322.485 & 1927.33032 \\
\hline
\end{tabular}

* \$4,924.72 is the EVSI the Farmer has to pay for hiring the services of the forecaster at the $40^{\text {th }}$ Iteration

Model Validation : The model was validated using Pearson correlation coefficient as can be seen in tables 8 (a), 8 (b) \& (c) and Figure 3 and Figure 4

Table 8 (b) : Pearson Product Moment Correlation Coefficientof Prior and Posterior Probability of $1^{\text {st }}$ Iteration

\begin{tabular}{|c|c|c|c|c|c|c|}
\hline \multicolumn{7}{|c|}{ Pearson Product Moment Correlation Coefficient } \\
\hline Prior & Posterior & $\mathbf{x}$ & $\mathbf{Y}$ & $\mathbf{x y}$ & $x^{\wedge} 2$ & $y^{\wedge} 2$ \\
\hline 0.686155614 & 0.635198559 & 0.436155614 & 0.38519856 & 0.168006514 & 0.190232 & 0.14837793 \\
\hline 0.042382077 & 0.045494527 & -0.207617923 & -0.2045055 & 0.042459002 & 0.043105 & 0.041822489 \\
\hline 0.231122742 & 0.266283791 & -0.018877258 & 0.01628379 & -0.00030739 & 0.000356 & 0.000265162 \\
\hline 0.040339567 & 0.053023123 & -0.209660433 & -0.1969769 & 0.041298257 & 0.043957 & 0.03879989 \\
\hline 1.00 & 1 & 0 & 0 & 0.25145638 & 0.277651 & 0.229265471 \\
\hline & & \multicolumn{2}{|l|}{$R=0.9967$} & & & \\
\hline
\end{tabular}




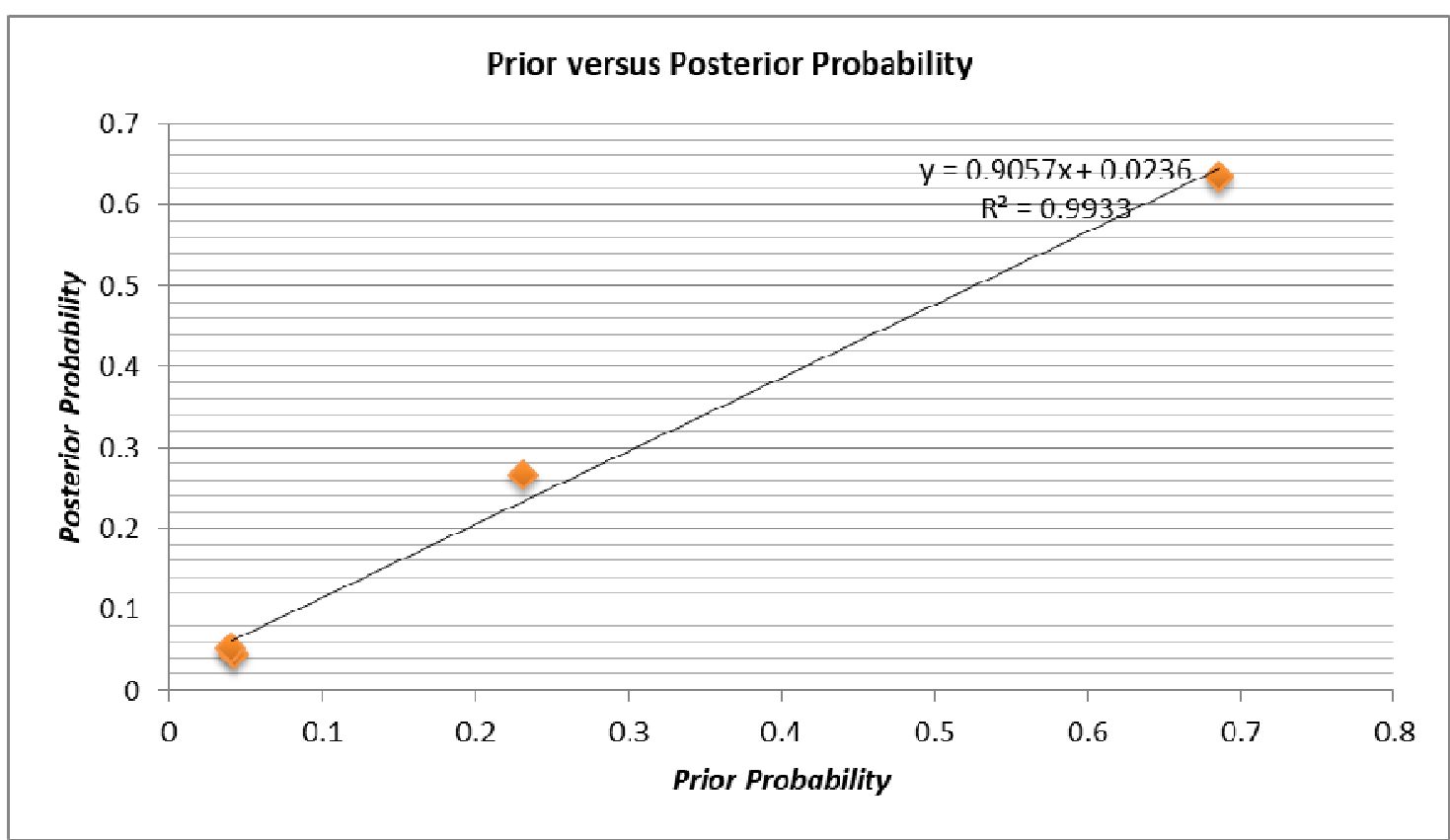

Figure 3: Relationship between Prior and Posterior Probability of the $1^{\text {st }}$ Iteration

Table 8 (c) : Pearson Product Moment Correlation Coefficient ofPrior and Posterior Probability of $40^{\text {th }}$ Iteration.

\begin{tabular}{|r|r|r|r|r|r|r|}
\hline \multicolumn{7}{|c|}{ Pearson Product Moment Correlation Coefficient } \\
\hline Prior & Posterior & \multicolumn{1}{|c|}{$\mathbf{X}$} & $\mathbf{y}$ & $\mathbf{X y}$ & \multicolumn{1}{c|}{$\mathbf{x}^{\wedge} \mathbf{2}$} & $\mathbf{y}^{\wedge} \mathbf{2}$ \\
\hline 0.01 & 0.007125308 & -0.24 & -0.2428747 & 0.058289926 & 0.0576 & 0.058988116 \\
\hline 0.02 & 0.016524322 & -0.23 & -0.2334757 & 0.053699406 & 0.0529 & 0.054510892 \\
\hline 0.04 & 0.035471436 & -0.21 & -0.2145286 & 0.045050998 & 0.0441 & 0.046022505 \\
\hline 0.93 & 0.940878935 & 0.68 & 0.69087893 & 0.469797676 & 0.4624 & 0.477313703 \\
\hline 1.00 & 1 & 0 & 0 & 0.626838006 & 0.617 & 0.636835216 \\
\hline \multicolumn{2}{|r|}{} & $\mathbf{R}=$ & $\mathbf{1 . 0 0 0 0}$ & & & \\
\hline
\end{tabular}

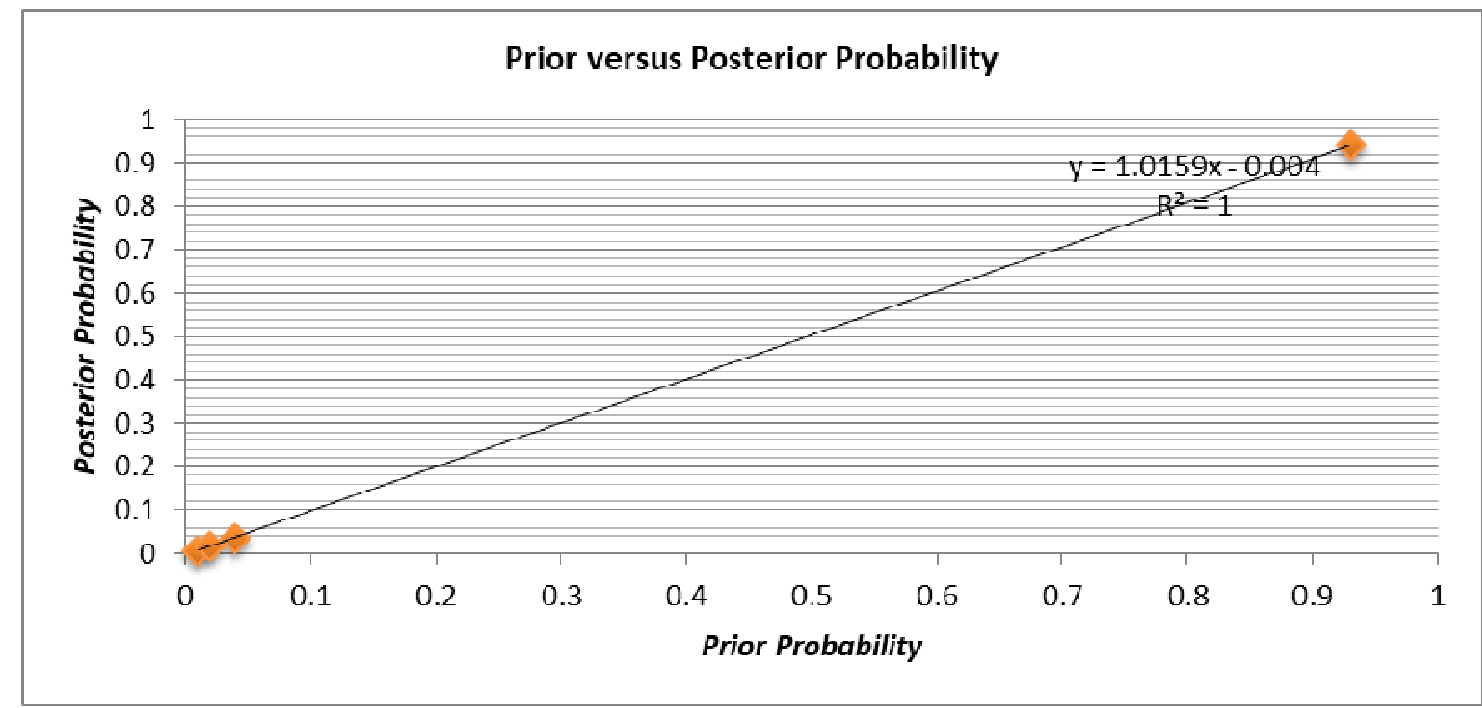

Figure 4: Relationship between Prior and Posterior Probability of the $40^{\text {th }}$ Iteration

\subsection{Discussion and Conclusion}

(a) The application of Bayesian Decision theory on Farmers' decision problem resulted to the following results:

A decision was finally established by the farmer to choose Rice as a crop among other alternatives for an 
investment; since it had the highest yield. This implies that Rice will produce more money for the farmer under rain field and irrigation process in Obudu Farm Project. However, in accordance with model output, Rice as a chosen cereal crop had the following parameters outputs:

$1^{\text {st }}$ iteration EMV values $=\mathbf{\$ 1 4 , 1 9 5 . 6 6}$ and $40^{\text {th }}$ Iteration EMV values $=\mathbf{\$ 1 7 , 1 7 8 . 2 1}$

$1^{\text {st }}$ iteration EVSI values $=\mathbf{\$ 6 , 8 9 1 . 9 5}$ and $40^{\text {th }}$ Iteration EVSI values $=\mathbf{\$ 4 , 9 2 4 . 7 2}$

Furthermore Rice has the highest comparative Monetary Value of $62 \%$ as shown in Figure 5 below.

\section{Expected Monetary Values of The Cereal Crops}

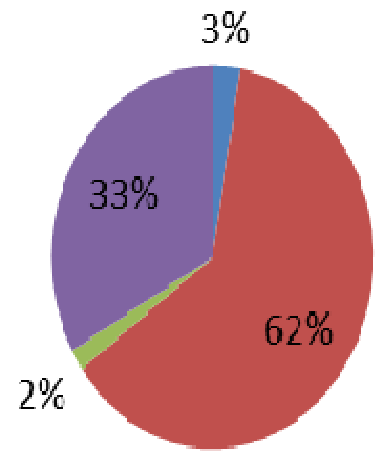

Sorghum

Rice

Wheat

Corn

Figure 5: Expected Monetary Values of the Cereal Crops at $40^{\text {th }}$ Iteration

\subsection{Model Optimization}

The Expected Monetary Values of the Cereal Crops were optimized. The value of Rice was optimized from $1^{\text {st }}$ iteration to $40^{\text {th }}$ Iteration with the EMV values of $\$ 14,195.66$ to $\$ 17,178.21$ respectively. Each of the Farm Settler makes addition money of $\$ 2,982.55$ after optimization.

Also, the Farmer is expected to pay the Forecaster/Consultant the Expected Value of System Information $($ EVSI $)=\$ \mathbf{4 4 9 2 4 . 7 2}$, for information generated using the Bayesian Decision theory model spreadsheet at $40^{\text {th }}$ iteration. However, there was a savings of $\mathbf{\$ 1 , 9 6 7 . 1 3}$ after optimization process from $1^{\text {st }}$ iteration to $40^{\text {th }}$ Iteration with the EVSI values reduced from $\mathbf{\$ 6 , 8 9 1 . 9 5}$ down to $\$ \mathbf{4 , 9 2 4 . 7 2}$.

\subsubsection{Model Validation}

The Pearson Product Moment Correlation Coefficient of Prior \& Posterior of the $1^{\text {st }}$ iteration gave a value of $\mathrm{R}=0.9967$.

Furthermore, the Pearson correlation coefficient of Prior \& Posterior at the $40^{\text {st }}$ iteration gave a value of $r=1$.

Conclusively, the Pearson reliability test on the study came up in a high performance; this is an indication of a 100 percentage of performance.

In conclusion the Author developed and applies powerful BDT Excel Algorithms [Payoff Matrix table] which can be applied in a wide variety of fields, most especially in River Basin Multi-projects/objectives Planning and Management.

\section{References}

Adrian, e. R. (1964). University of Washington (1994), Technical Report no. 254 Department of Statistics, University of Washington Technical Report no. 571.

Alene, A.D.. et al. (2009) The Economic and Poverty Impacts of Maize Research in West and Central Africa.

Agricultural Economics,40: 535-550.

Amy, H. and Leaf, G. (2018). Climate of Obudu, Nigeria, traveltips.usatoday.com

Ayoade, J.O. (1983) Introduction to Climatology for the Tropics. Spectrum Book Ltd, Ibadan.

Bagley, L., Jay, M.., Rolaad, W. J. aad Cleve, H. M. (1964) . Water yie ld s ia Utah . Utah Agricultural Experiment Station, Spec ial Report 18 . September .

Balasubramanian, V., Sie, M., Hijmans, R., Otsuka, K., (2007). Increasing rice production in Sub-Saharan Africa: Challenges and Opportunities. Advances in Agronomy,94:55-133.

Barbey, A. K. \& Sloman, S. A. (2007). Base-rate Respect: FromEecological Rationality to dual Processes. Behavioral and Brain Sciences, 30: 241-254.

Baudron et al, (2015). Re-examining Appropriate Mechanization in Eastern and Southern Africa: Two-wheel Tractors, Conservation Agriculture, and Private Sector Involvement, Food Security, May. 
Bullock , B. J . \& Logaa, S. H. (1969) . A Model for Decision Making under Uncertainty. Agricultural Ecoaomics Research,21(4) : 857.

Eme L.C. (2010). Water Resources Engineering Development Scheme: Optimal Strategy for Multipurpose/Multi-objective Water Resources Engineering Development Scheme. InternationalJournal of Civil Engineering, 2(1): 49 - 56.

Eme L.C. (2010). Water Resources Engineering Development Scheme: Optimal Strategy for Multipurpose/Multi-objective Water Resources Engineering Development Scheme. African Journal of Engineering Research and Development, 3(3): 27 - 33.

Eme L.C. (2011). Application of Markovia Decision Theory in Multi-purpose/Multi-Objective Dam Development Project Optimization. Journal of Research in Engineering, 8(2): 70-74.

USDA, Production Estimates and Crop Assessment Division (PECAD) Foreign Agricultural Service (FAS) http://fas.usda.gov/pecad/pecad.html 